\title{
The Effect of Epidural Neostigmine Combined with Levobupivacaine on Neuraxial Analgesia during Labor
}

\author{
HORIA A. FARRAN, M.D. and ABEER E. FARHAT, M.D.
}

The Department of Anesthesiology, Intensive Care and Pain Management, Faculty of Medicine for Girls, Al-Azhar University

\begin{abstract}
Background: Neuraxial analgesia is the gold standard for conducting painless labor either by epidural route or combined spinal epidural.

Aim of Study: This study is to evaluate the effect of adding neostigmine to levobupivacaine for epidural labor analgesia on mother and neonate.

Patient and Methods: After approval from local ethical committee and obtaining written informed consent this prospective randomized double-blind study was conducted on 60 laboring mothers, aged between 21 to 38 years, ASA I \& II, single pregnancy, gestational age $>! 37$ weeks in active cervical dilatation $(195 \mathrm{~cm})$ subjected to normal labor by epidural analgesia. Parturient were randomly divided into two groups: Group L ( $\mathrm{n}=30$ ): Received $15 \mathrm{ml}$ of $0.125 \%$ levobupivacaine. Group N ( $\mathrm{n}=30$ ): Received $15 \mathrm{ml}$ of $0.125 \%$ levobupivacaine $+6 \mathrm{mic} / \mathrm{kg}$ neostigmine. Onset of sensory block, duration of analgesia, maternal hemodynamics, motor block and total dose of levobupivacaine were recorded. Maternal outcome in the form of (duration of labor, mode of delivery), Apgar score at ( 1 and $5 \mathrm{~min})$ and side effects were also recorded.
\end{abstract}

Results: There was faster onset of sensory block and prolonged duration of analgesia with neostigmine group compared with other group. No significant difference between both groups as regard hemodynamics. No motor blockade in both groups. There was significant reduction in the total dose of levobupivacaine with neostigmine group. There was shorter duration of labor with neostigmine group. No significant difference as regard mode of delivery, Apgar score and complications between the two groups.

Conclusion: Neostigmine can be utilized as a safe adjuvant with levobupivacaine to provide a better quality of analgesia and reduce dose of local anesthetic during management of labor pain. Also it's safe for both mother and fetus.

Key Words: Neostigmine - Levobupivacaine - Labor epidural analgesia.

Correspondence to: Dr. Horia A. Farran, The Department of Anesthesiology, Intensive Care and Pain Management, Faculty of Medicine for Girls, Al-Azhar University

\section{Introduction}

NEURAXIAL analgesia is the gold standard for conducting painless labor either by epidural route or combined spinal epidural [1], recent local anesthetic agents such as ropivacaine and levobupivacaine with relatively better safety profiles are used for producing such analgesia in consenting parturient without contraindications [2]. The current practice in obstetric anesthesia is usually to use small doses of epidural local anesthetics with an adjuvant drug to produce selective analgesia [3] .

Neuraxial adjuvants are utilized to provide higher analgesia and to lessen facet effects related with excessive dose of local anesthetics [4]. Neuraxial opioids are usually associated with side effects such as respiratory depression, sedation, urine retention, nausea and vomiting [5]

Neostigmine is a cholinesterase inhibitor, which hinders the breakdown of endogenous spinal acetyl choline, indirectly stimulates muscarinic and nicotinic receptors and provides analgesia [6]. Acetylcholine induces analgesia by increasing cGMP by generating nitric oxide. Neostigmine increases sympathetic outflow so, avoid the hypotensive effect of local anesthetics [7].

Spinal neostigmine produces analgesia but causes sever nausea and vomiting may be due to cephalic spread and action in the brain stem [7] Epidural neostigmine is safe in obstetric population with no reported side effects for both mother and fetus [4].

Levobupivacaine is a pure S-enantiomer of bupivacaine [8] it is similar to bupivacaine but less toxic to cardiac and central nervous system than bupivacaine. Low concentrations of levobupivacaine produce selective sensory block with preservation of motor function [9] 


\section{Patients and Methods}

After approval from Local Ethical Committee and obtaining written informed consent this prospective randomized double-blind study was conducted in Al-Zahraa University Hospital in the period between November 2018 to May 2019. The study included 60 laboring mothers, aged between 21 to 38years, American society of anesthesiologists (ASA) I \& II, singleton pregnancy, gestational age $>37$ weeks in active cervical dilatation $(<5 \mathrm{~cm})$ subjected to normal vaginal delivery by epidural analgesia. Exclusion criteria were history of allergy to the study drugs, patients having any contraindications to neuraxial blocks, patients with history of (uncontrolled hypertension or diabetes) and obstetric complications (multiple pregnancy, premature labor or non-vertex presentation). Complete pre-anesthetic checkup was done and all patients completed the fasting hours and instructed about the epidural procedures and Visual Analogue Scale (VAS) which used for pain assessment. In the recovery room, after securing 18 gauge intravenous cannula, preloading was given with $10 \mathrm{ml} / \mathrm{kg}$ lactated ringer solution. In the operating room, lumber epidural block was performed in sitting position at L3-4 after complete aseptic precaution and local infiltration with $3 \mathrm{ml}$ of $2 \%$ lidocaine. $20 \mathrm{G}$ catheter was inserted $3-4 \mathrm{~cm}$ inside the epidural space via1 8G Tuohy needle (perifix, Braun, Melsungen, Germany) after loss of resistance technique then patient was positioned in the supine left lateral position, a test dose of $3 \mathrm{ml}$ of lidocaine plus epinephrine $5 \mu \mathrm{g} / \mathrm{ml}$ was given via the catheter after negative aspiration (to CSF and blood). Patients were randomly assigned by (computer generated number and sealed envelope technique) into two groups:

- Group L ( $\mathrm{n}=30$ ): Given $15 \mathrm{ml}$ of $0.125 \%$ levobupivacaine (Abbvie, Curida AS, Norway, Italy).

- Group N (n=30): Given $15 \mathrm{ml}$ of $0.125 \%$ levobupivacaine $+6 \mathrm{mic} / \mathrm{kg}$ neostigmine.

Both patient and anesthetist who performed the block were blinded to the study drugs.

Maternal hemodynamics [Heart Rate (HR), Mean Arterial Pressure (MAP), ( $\left.\left.\mathrm{SPO}_{2}\right)\right]$ and VAS score for pain assessment were recorded before insertion of epidural catheter and every $5 \mathrm{~min}$ for 30min after administration of the study drugs then at one hour interval until delivery. Onset of sensory block (assessed by ether test) and degree of motor block in lower limb (assessed by modified Bromage scale) were recorded. Duration of analgesia (time elapsed from first epidural injection to patient's request for further analgesia) and the total dose of levobupivacaine were recorded. Duration of labor, mode of delivery, Apgar score at (1 and 5min) and adverse effects were also recorded.

The primary outcome was the duration of analgesia and secondary outcomes were onset of sensory block, motor block, maternal hemodynamic, total dose of local anesthetic, VAS score, maternal outcome (duration of labor, mode of delivery), Apgar score at ( $1 \& 5 \mathrm{~min})$ and adverse effects.

Maternal bradycardia is defined as fall in HR $<60$ beats/min and treated with IV atropine $(0.01$ $\mathrm{mg} / \mathrm{kg}$ ). Maternal hypotension is defined as fall in MAP $>20 \%$ of baseline value and treated with IV fluid and ephedrine (6mg IV increments). Nausea and vomiting was treated by metoclopramide $10 \mathrm{mg}$ IV.

\section{Statistical analysis and sample size calculation:}

To detect clinically significant difference of duration of analgesia between both groups, with the power of $80 \%$ and a error of 0.05 using stratified random sampling the calculated sample size was found to be 27 patients in each group considering the dropouts, we had included sample size of 30 in each group.

Data were gathered, revised, coded and entered to the Statistical Package for Social Science (IBM SPSS) version 23 . The quantitative data were introduced as mean, standard deviations and ranges when parametric. Also qualitative variables were introduced as number and percentages. The correlation between groups with respect to qualitative data was done by using Chi-square test and/or Fisher exact test when the expected count in any cell found less than 5 . The correlation between two independent groups with quantitative data and parametric distribution was done by using Independent $t$-test. The confidence interval was set to $95 \%$ and the margin of error accepted was set to $5 \%$. So, the $p$-value was considered significant as the following: $p$-value $<0.05$ : Significant $(\mathrm{S})$.

\section{Results}

There was no significant difference between both groups regarding demographic data as shown in (Table 1).

There were faster onset, longer duration of analgesia and significant decrease in the total dose of levobupivacaine with neostigmine group when compared to group L but no differences as regard level of sensory and motor block as shown in Table (2). 
Table (1): Demographic data in both groups (mean $\pm \mathrm{SD}$ ).

\begin{tabular}{lcccc}
\hline & $\begin{array}{c}\text { Group L } \\
(\mathrm{n}=30)\end{array}$ & $\begin{array}{c}\text { Group N } \\
(\mathrm{n}=30)\end{array}$ & $\begin{array}{c}\text { Test } \\
\text { value }\end{array}$ & $\begin{array}{c}p^{-} \\
\text {value }\end{array}$ \\
\hline Age (years) & $27.63 \pm 5.37$ & $29.93 \pm 6.24$ & $-1.531 \bullet$ & 0.131 \\
Height (cm) & $161.33 \pm 1.1$ & $161.36 \pm 1.1$ & 0.085 & 0.932 \\
Body weight (kg) & $70.43 \pm 6.13$ & $72.18 \pm 5.00$ & $-1.209 \bullet$ & 0.232 \\
ASA physical status: & & & & \\
$\quad$ I & $22(73.3 \%)$ & $21(70.0 \%)$ & $0.082 *$ & 0.774 \\
$\quad$ II & $8(26.7 \%)$ & $9(30.0 \%)$ & & \\
\hline
\end{tabular}

$p$-value $>0.05$ : Non Significant (NS).

$p$-value $<0.05$ : Significant (S).

$p$-value <0.01: Highly Significant (HS).

*: Chi-square test.

•: Independent $t$-test.

$\mathrm{SD}=$ Standard deviation.

ASA = American Society of Anesthesia

Table (2): Comparison between the two groups regarding sensory block and analgesic characteristics (mean $\pm \mathrm{SD})$.

\begin{tabular}{|c|c|c|c|c|}
\hline & $\begin{array}{l}\text { Group L } \\
(\mathrm{n}=30)\end{array}$ & $\begin{array}{c}\text { Group N } \\
(\mathrm{n}=30)\end{array}$ & $\begin{array}{c}\text { Test } \\
\text { value }\end{array}$ & $\underset{\text { value }}{p^{-}}$ \\
\hline $\begin{array}{l}\text { - Onset of sensory } \\
\text { block (min) }\end{array}$ & $15.03 \pm 0.58$ & $10.24 \pm 0.56$ & $32.542 \bullet$ & 0.000 \\
\hline $\begin{array}{l}\text { - Level of highest } \\
\text { sensory block }\end{array}$ & $\mathrm{T} 10$ & $\mathrm{~T} 10$ & NA & NA \\
\hline $\begin{array}{l}\text { - Duration of } \\
\text { analgesia (hr) }\end{array}$ & $3.58 \pm 0.54$ & $7.45 \pm 0.90$ & 20.196 & 0.000 \\
\hline - Motor block & $0 \quad(0.0 \%)$ & $0(0.0 \%)$ & $0.000 *$ & 1.000 \\
\hline $\begin{array}{l}\text { Second dose of } \\
\text { levobupivacaine } \\
\text { (n of patient) }\end{array}$ & $23(76.7 \%)$ & $0(0.0 \%)$ & $37.297^{*}$ & 0.000 \\
\hline $\begin{array}{l}\text { Total dose of } \\
\text { levobupivacaine } \\
\text { (mg/patient) }\end{array}$ & $31.25 \pm 44.54$ & $15.50 \pm 0.5$ & 1.937 & 0.0577 \\
\hline $\begin{array}{l}p \text {-value }>0.05: \text { Non } \\
p \text {-value }<0.05: \text { Sign } \\
p \text {-value }<0.01: \text { High }\end{array}$ & $\begin{array}{l}\text { onificant (1 } \\
\text { cant }(\mathrm{S}) \text {. } \\
\text { significan }\end{array}$ & & \multicolumn{2}{|c|}{$\begin{array}{l}\text { *: Chi-square test. } \\
\bullet: \text { Independent. }\end{array}$} \\
\hline
\end{tabular}

There was significant decrease in VAS Score at $10 \mathrm{~min}$ and at 3 hours in neostigmine group when compared with group L as shown in Fig. (1).

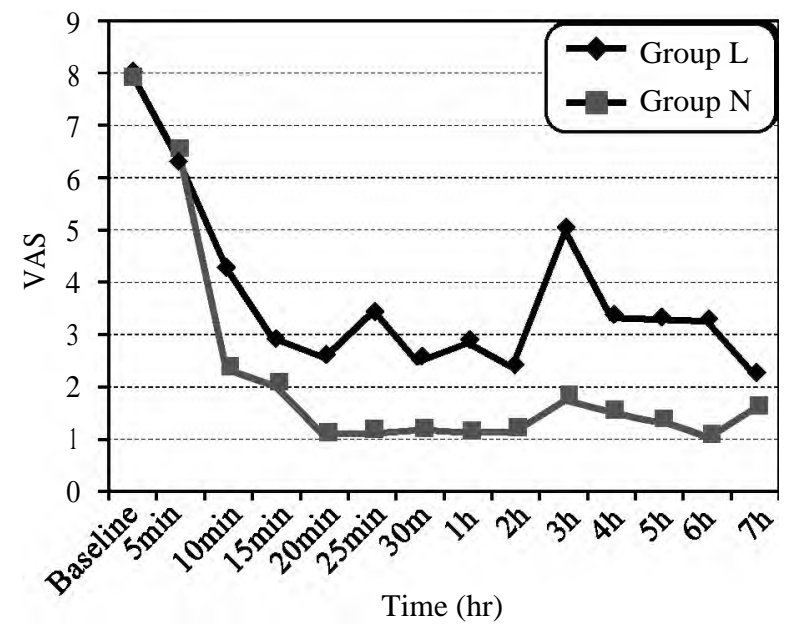

Fig. (1): VAS score in the two studied groups.
There was no statistical difference between the two groups regarding HR as shown in Fig. (2).
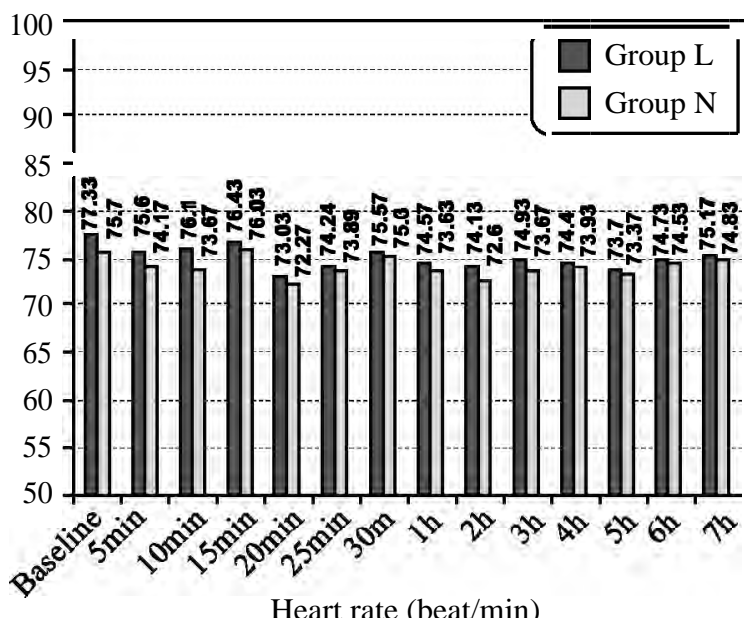

Fig. (2): Comparison between the two groups as regard maternal heart rate (beat/min).

Regarding MAP (mmHg) there was no significant difference between both groups as shown in Fig. (3).

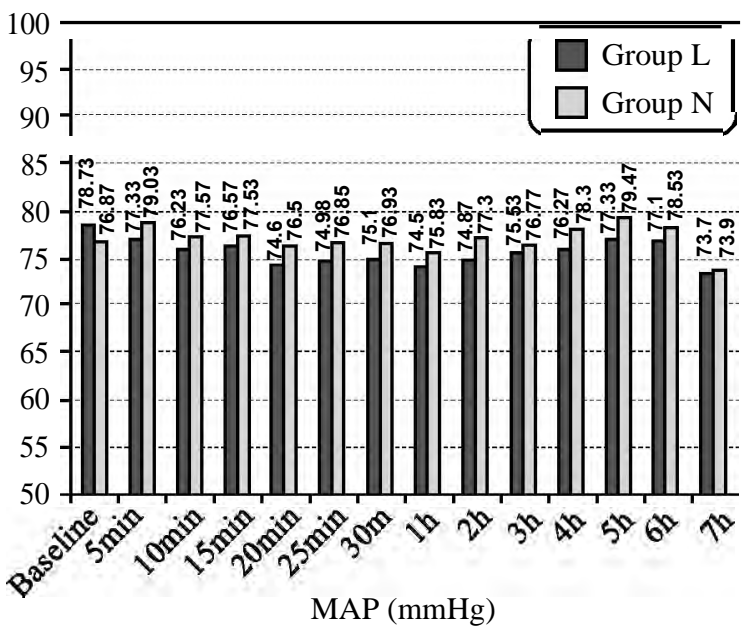

Fig. (3): Comparison between the two groups regarding maternal MAP $(\mathrm{mmHg})$.

There was significant decrease in Total time of delivery with neostigmine group but no differences regarding mode of delivery and Apgar score between the two groups as shown in (Table 3).

There were no significant differences between the two studied groups regarding side effects as shown in (Table 4).

Only one case developed hypotension in group $\mathrm{L}$ and treated with intravenus fluid.

Another case developed nausea and vomiting in group $\mathrm{L}$ and treated by metoclopramide $10 \mathrm{mg}$ IV. 
Table (3): Comparison between the two groups as regard obstetric characteristics (mean $\pm \mathrm{SD}$ ).

\begin{tabular}{|c|c|c|c|c|}
\hline & $\begin{array}{c}\text { Group L } \\
(\mathrm{n}=30)\end{array}$ & $\begin{array}{c}\text { Group N } \\
(\mathrm{n}=30)\end{array}$ & $\begin{array}{c}\text { Test } \\
\text { value }\end{array}$ & $\begin{array}{c}p- \\
\text { value }\end{array}$ \\
\hline $\begin{array}{l}\text { - Cervical dilatation } \\
\text { at injection }\end{array}$ & $5(16.7 \%)$ & $5(16.7 \%)$ & $0.000 *$ & 1.000 \\
\hline $\begin{array}{l}\text { - Cervical dilatation } \\
\text { after } 1 \mathrm{hr}\end{array}$ & $6(20.0 \%)$ & $7(23.3 \%)$ & $0.098^{*}$ & 0.754 \\
\hline $\begin{array}{l}\text { Total time of } \\
\text { delivery (hr) }\end{array}$ & $6.02 \pm 0.30$ & $4.08 \pm 0.36$ & $22.675 \bullet$ & 0.000 \\
\hline \multicolumn{5}{|l|}{ - Mode of delivery: } \\
\hline Normal & $28(93.3 \%)$ & $29(96.7 \%)$ & $0.351 *$ & 0.554 \\
\hline $\mathrm{CS}$ & $2(6.7 \%)$ & $1 \quad(3.3 \%)$ & & \\
\hline Instrumental & $0.00 \%$ & $0.00 \%$ & & \\
\hline - Apgar score at $1 \mathrm{~min}$ & $8.67 \pm 0.55$ & $8.57 \pm 0.68$ & $-0.628 \bullet$ & 0.532 \\
\hline - Apgar score at $5 \mathrm{~min}$ & $9.72 \pm 0.47$ & $9.81 \pm 0.42$ & $0.782 \bullet$ & 0.437 \\
\hline $\begin{array}{l}p \text {-value }>0.05: \text { Non } s \\
p \text {-value }<0.05: \text { Signif } \\
p \text {-value }<0.01: \text { Highly }\end{array}$ & $t(\mathrm{~N}$ & & $\begin{array}{l}\text { : Chi-squ } \\
\text { : Indepen }\end{array}$ & $\begin{array}{l}\text { test. } \\
\text { tt. }\end{array}$ \\
\hline
\end{tabular}

Table (4): Comparison between the two groups regarding side effects (mean $\pm \mathrm{SD}$ ).

\begin{tabular}{lcccc}
\hline Side effects & $\begin{array}{c}\text { Group L } \\
(\mathrm{n}=30) \%\end{array}$ & $\begin{array}{c}\text { Group N } \\
(\mathrm{n}=30) \%\end{array}$ & $\begin{array}{c}\text { Test } \\
\text { value* }\end{array}$ & $\begin{array}{c}p \text { - } \\
\text { value }\end{array}$ \\
\hline Bradycardia & $0(0.0 \%)$ & $0(0.0 \%)$ & 0.000 & 1.000 \\
Hypotension & $1(3.3 \%)$ & $0(0.0 \%)$ & 1.017 & 0.313 \\
Nausea and vomiting & $1(3.3 \%)$ & $0(0.0 \%)$ & 1.017 & 0.313 \\
Shivering & $0(0.0 \%)$ & $0(0.0 \%)$ & 0.000 & 1.000 \\
\hline
\end{tabular}

$p$-value $>0.05$ : Non Significant (NS).

$p$-value $<0.05$ : Significant (S).

$p$-value <0.01: Highly Significant (HS).

*: Chi-square test.

\section{Discussion}

Epidural analgesia is the most efficient and the most common technique for painless labor. Neuraxial adjuvants are utilized to provide higher analgesia and to lessen facet effects related with excessive dose of local anesthetics.

In the present study we assess the effect of adding neostigmine to levobupivacaine during management of labor pain on 60 pregnant female subjected to normal labor by epidural analgesia regarding onset, duration of analgesia, total dose of levobupivacaine, maternal and neonatal effects.

As respect to onset and duration of analgesia. The results of our the other study were faster onset and longer duration of analgesia with neostigmine group compared to levobupivacaine group. Because neostigmine increases the concentration of acetylcholine in the synapse and thus enhances acetylcholine mediated mechanisms of analgesia. It inhibits central sensitization, blocks transmission of feeling of harm from the spinal cord and produces antinociception [10].
Our results are matching with the results conducted by Rajneendra et al. [11] they evaluated 120 patients, randomly allocated them into four groups each received either saline, 50,100 or 150 , mic neostigmine in $1 \mathrm{ml}$ as adjuvant to levobupivacaine $0.5 \% 20 \mathrm{ml}$ epidural and they concluded that coadministration of epidural neostigmine and levobupivacaine increases the duration of analgesia without increasing side effects. Our results went in line with the study conducted by Pavani et al., [7] they concluded that co-administration of epidural neostigmine and bupivacaine provides faster onset and longer duration.

As regard maternal hemodynamic, there were no significant differences between the two groups. Absence of maternal hypotension may be attributed to that neostigmine increases sympathetic outflow, so abolish the hypotension of local anesthetics. Our study results are in agreement with the study conducted by Chaurasia et al., [4] they studied 90 patients randomly allocated into three groups received neostigmine $7 \mathrm{~g} / \mathrm{k}$. plus either butorphanol $1 \mathrm{mg}$, sufentanil 10 o. $0.9 \%$ normal saline, they founded no changes in maternal hemodynamics.

Also we agree with the study of Pavani et al., [7] they studied the comparison between epidural Neostigmine with Bupivacaine and Bupivacaine alone on 100 patients, they founded no fluctuations in blood pressure or change in heart rate, except for one patient who developed bradycardia.

Our results disagree with Khalaf [12] who studied 60 Laboring mothers randomly divided into two groups received ropivacaine $0.15 \%$ + either Neostigmine $4 \mathrm{mcg} / \mathrm{ml}$ or Fentanyl $2 \mathrm{mcg} / \mathrm{ml}$ and indicated that there was hypotension in both groups at the start of epidural labor analgesia which may be due to the use of ropivacaine, prolonged starvation and hypovolemia of the laboring mothers.

There was marked decrease in pain score at $10 \mathrm{~min}$ and 3 hours with neostigmine group compared to levobupivacaine group, this may be explained by that a combination of neostigmine with levobupivacaine have an additive effect. Our results are in agreement with the results of Chauarisa [4] and Khalaf [12].

Both results revealed significant decrease in VAS score with neostigmine group. On the other hand, Booth et al., [13] studied 215 parturients requested labor epidural analgesia and received $0.125 \%$ bupivacaine with either neostigmine $(2$, 4 , or $8 \mathrm{~g} / \mathrm{n}-1)$ or fentanyl $(2 \mathrm{~g} / \mathrm{n}-1)$ and founded no differences between the studied groups. 
As regard motor blockade, there was no motor block recorded in both groups. It may be due to that we chose to give low concentrations of levobupivacaine which produce selective sensory block with preservation of motor function [9]. This result is matched with the study of El-Sharaawy et al., [9] who compared three different concentrations of levobupivacaine for epidural labor analgesia and indicated that no motor blockade with the same concentration as we used in our study. Also we agree with Chaurasia et al., [4], Khalaf [12], Reolant and Lavand [3].

Regarding the total dose of levobupivacaine, there was significant reduction of total dose of levobupivacaine with neostigmine group compared to the other group. The result of the current study matches with the result of Ning and Ming [10] they studied 280 patients, and concluded that epidural neostigmine and clonidine significantly prolong the initial analgesia and reduce hourly local anesthetics. We also agree with Ross et al., [14], who studied low dose of epidural neostigmine $(4 \mathrm{mic} / \mathrm{ml})$ for labor analgesia and concluded that it reduces the dose of epidural bupivacaine $25 \%$ without significant side effects for mother and fetus. Also we agree with Chaurasia et al., [4] and Khalaf [12].

On the other hand, Booth et al., [13] founded no differences between the studied groups regarding the dose of local anesthetic.

Regarding the duration of labor, there was shorter duration of labor with neostigmine group. Our results met with Lauretti [15] but disagree with Booth et al., [13] and Khalaf [12]

As regard mode of delivery, there was no significant difference between the two groups. The same result was observed by Roelants and Lavand [16]. Also we agree with the study of Booth et al., [13] and Khalaf [12]. But disagree with the result of Ning and Ming [10].

Regarding maternal side effects there was no significant difference between the two studied groups. Neostigmine causing severe nausea and vomiting in subarachnoid block may be due to cephalad spread and action in brain stem. This is not detected with epidural neostigmine [7].

There is matching between our results and the results of Ross et al., [14], who studied low dose of epidural neostigmine $(4 \mathrm{mic} / \mathrm{ml})$ for labor analgesia and observed that it reduce the dose of epidural bupivacaine $25 \%$ without significant side effects to mother and fetus. Also we agree with
Cossu et al., [5], Booth et al., [13] and Rajneendra et al., [11].

Regarding fetal outcome, there was no effect (bradycardia during labor or low Apgar score) on the neonate recorded in the current study, which can be attributed to the maternal hemodynamic stability due to low concentration of levobupivacaine, also we chose to administer a dose of $6 \mathrm{mic} / \mathrm{kg}$ neostigmine to avoid systemic reabsorption of neostigmine into the maternal circulation after epidural route which can cause fetal bradycardia as it cross the placenta and cause increase of fetal vagal tone [3]. These results are matching with Rajneendra et al., [11]

Our results also met with the results of Chaurasia et al., [4], Roelants [3], and Booth et al., [13].

\section{Conclusion:}

Neostigmine can be utilized as a safe adjuvant with levobupivacaine to provide a better quality of analgesia and reduce the dose of local anesthetic during management of labor pain. Also, it's safe for both mother and fetus.

\section{References}

1- WONG C.A.: Labor analgesia: Is there ideal technique? Anesth. Analg., 109: 296-8, 2009.

2- ALI H.M. and WAHDAN A.: Using dexamethasone as an adjuvant to levobupivavaine in epidural anesthesia to change the pain intensity and duration in painless labor. Saudi J. Anaesth., 12: 209-14, 2018.

3- ROELANTS F., RIZOO M. and LAVAND HOMME P. The effect of Epidural neostigmine combined with ropivacaine and sufentanil on neuraxial analgesia during labor. Anesthesia and Analgesia., 96: 1161-6. (Pub Med), 2003.

4- CHAURASIA M., SAXENA A.K. and CHILKOTI G.T.: Comparison of Epidural Butorphanol with Neostigmine and Epidural Sufentanyl with Neostigmine for First Stage of Labor Analgesia: A Randomized Controlled Trial. Anesthesia, Essays and Researches, 11 (2): 365, 2017.

5- COSSUA A.P. and De GIUDICIB L.M., PIRAS D., MURA P., SCANU M., SABA G., et al.: A systematic review of the effects of adding neostigmine to local anesthetics for neuraxial administration in obstetric anesthesia and analgesia. Int. J. Obstet. Anesth., 24: 237-46. (Pub Med), 2015.

6- HOOD D.D., EISENACH J.C. and TUTTLE R.: Phase I safety assessment of intrathecal neostigmine methylsulfate in humans. Anesthesiology, 82: 331-43, 1995.

7- PAVANI I., RAGHUPATRUNI V. and KUMARI B.J.: Comparative study of epidural Bupivacaine and Bupivacaine with Neostigmine. J. of Evolution of Medical and Dental Sciences, 4: 7647-51, 2015.

8- FOSTER R.H. and MARKHAM A.: Levobupivacaine: A review of its pharmacology and use as a local anesthetic Drug, 59: 551-79 (Pub Med), 2000. 
9- EL-SHAARAW A.M., ASFOUR M.S., RASHWAN D.A., AMER M.M., EL-MENSHAWY S.F. and ELKOMY M.H.: Comparison of three different concentrations of levobupivacaine for epidural lobar analgesia: Clinical effect and pharmacological profile; Anesth. Essays Res., (1): 60-6, 2018

10- NING Z. and MING-JUN X.: Effects of epidural neostigmine and clonidine in labor analgesia: A systematic review and meta-analysis. J. Obstet. Gynaecol. Res., 41: 214-21, 2015.

11- RAJNEENDRA S., SEEMA P. and SAURABH B.: A comparative evaluation of three different doses of Epidural Neostigmine Co-administered with Levobupivacaine for post-operative analgesia after lower limb Orthopedic surgeries Indian Journal of Clinical Anesthesia, 3: 219$23,2016$.

12- KHALAF A.: Neostigmine versus Fentanyl administration with Ropivacaine by patient-controlled epidural analgesia for the management of labor pain. Ain-Shams Journal of Anesthesiology, 8: 211-114, 2015.

13- BOOTH J.L., ROSS V.H., NELSON K.E., HARRIS L., EISENACH J.C. and PAN P.H.: Epidural Neostigmine versus Fentanyl to Decrease Bupivacaine Use in Patientcontrolled Epidural Analgesia during Labor. Anesthesiology, 127: 50-7, 2017.

14-ROSS V.H., PAN P.H., OWEN M.D., SEID M.H., HARRIS L., CLYNA B., VOLTAIRE M. and EISENACH J.C. Neostigmine decreases Bupivacaine use by patientcontrolled epidural analgesia during labor: A randomized controlled study. Anesth. Analg., 109: 524-31, 2009.

15- LAURETTI G.R.: The evolution of spinal/epidural neostigmine in clinical application: Thoughts after two decades. Saudi J. Anesth., 9: 71-81, 2015.

16- ROELANT F. and LAVAND HOMME P.M.: Epidural neostigmine combined with sufentanil provides balanced and selective analgesia in early labor. Anaesthiology, 101: 439-44, 2004.

\title{
تأثير حقن عقار ثيوستيجمين فوق جنباً إلى جنب البـاء

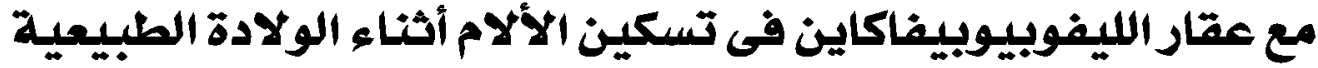

\author{
يعد استخدام التخدير الموضعى هو التقنية الذهبية والاكثر فعالية لتسكين الآلام أثناء الولادة الطبيعية إما عن طريق الحقن فوق الجافية \\ أو بطريقة الجمع بين الحقن فوق الجافية والشوكى. \\ كما يعتبر الاكثر شيوعاً في تخدير الولادات هو أن نجمع بين جرعات صغيرة من مخدر موضعى فوق الجافية مع إضافة أدوية مساعدة

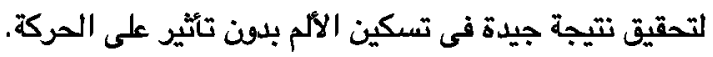 \\ تقوم الدراسة على تقييم تأثير إضافة عقار النيوستيجمين إلى عقار الليفوبيوبيفاكاين فوق الجافية لتسكين الألام أثثاء الولادة الطبيعية وتأثيره \\ على كلاً من الأم والجنين.

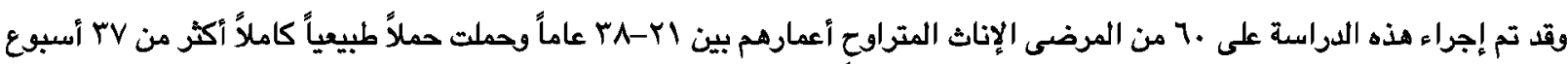

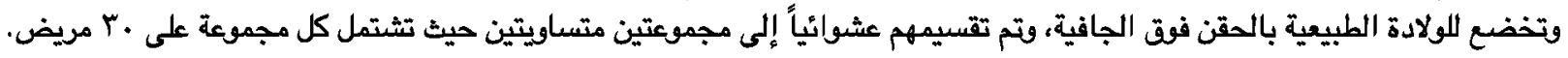 \\ - المجموعة الأولى تم حقنها بعقار الليفوبيوبيفاكاين. \\ - المجموعة الثانية تم حقنها بعقار الليفوبيوبيفاكاين + نيوستيجمين.
}

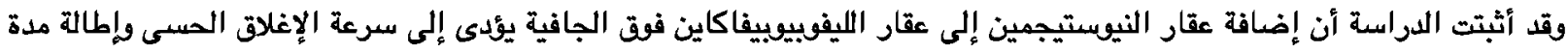

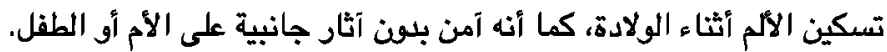

